\title{
A RARE CASE OF PLACENTA PERCRETA WITH UTERINE RUPTURE
}

B. Radhika ${ }^{1}$, Amodita Ahuja ${ }^{2}$

${ }^{1}$ Consultant, Department of Obstetrics and Gynaecology, Maxcure Suyosha Woman and Child Hospital, Madhapur, Hyderabad,

Telangana, India.

${ }^{2}$ Fellow, Department of Obstetrics and Gynaecology, Maxcure Suyosha Woman and Child Hospital, Madhapur, Hyderabad, Telangana, India.

HOW TO CITE THIS ARTICLE: Radhika B, Ahuja A. A rare case of placenta percreta with uterine rupture. J. Evolution Med. Dent. Sci. 2018;7(26):3079-3081, DOI: 10.14260/jemds/2018/691

\section{PRESENTATION OF CASE}

A 24-year-old patient referred to our hospital with the diagnosis of G3P1L1A1 with 21 weeks +3 days gestational age with previous LSCS complaining of severe pain in lower abdomen since 1 week. She had grade 3 pallor with tachycardia. Abdominal examination revealed 24 weeks size uterus with good foetal heart sounds. Tenderness was present all over lower abdomen below the umbilicus, more in left iliac fossa.

\section{CLINICAL DIAGNOSIS}

Patient was admitted in SICU and evaluated. Ultrasound showed single live intrauterine foetus of 21 weeks 4 days with cephalic presentation and short cervix of $2.5 \mathrm{~cm}$. Placenta praevia covering the os? Placenta percreta. Fluid collection with septations measuring $88 \times 66 \times 29 \mathrm{~mm}$ was seen in left iliac fossa adjacent to uterine surface, probably haematoma.

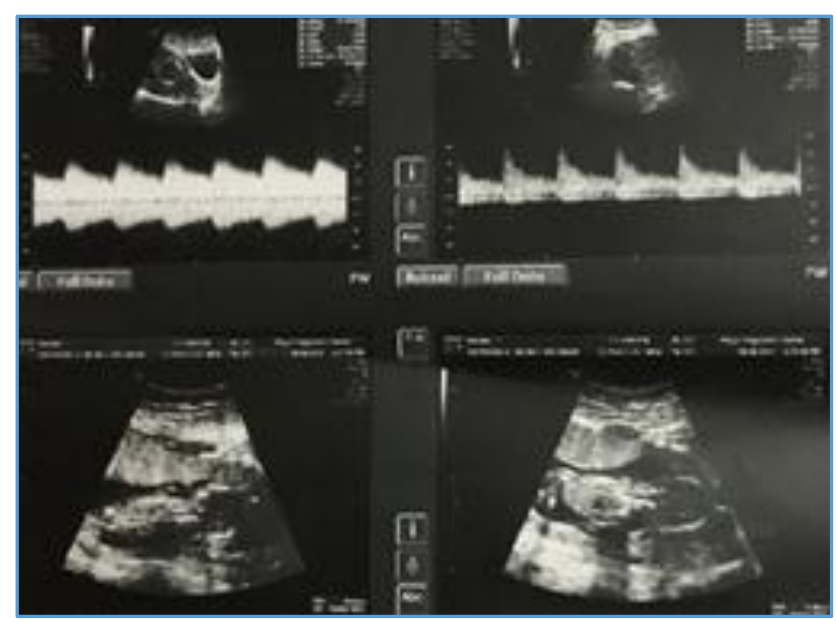

Placenta Praevia covering the Os? Placenta Percreta

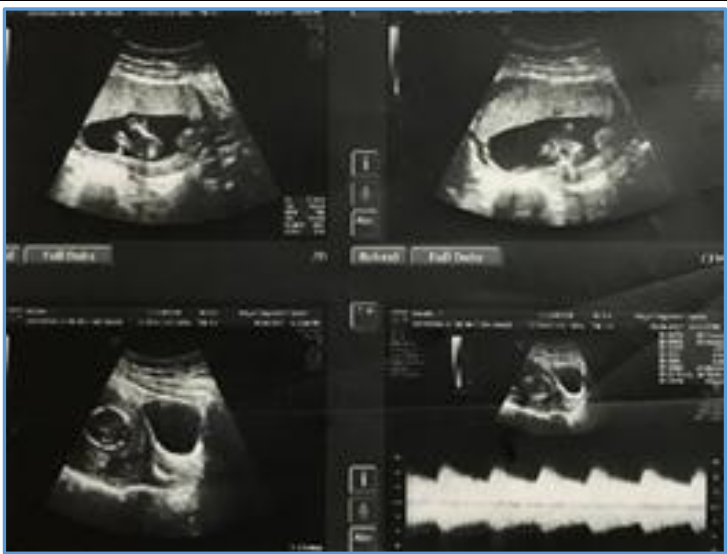

Single Live Foetus of 21 weeks 4 days with Cephalic Presentation with Short Cervix

Further evaluation was done with MRI. MRI also revealed organised haematoma, secondary to ruptured periplacental varicosity. There was possibility of placenta percreta.

Her haemoglobin level was $6.3 \mathrm{~g} / \mathrm{dL}$. Other investigations showed low plasma fibrinogen of $137.8 \mathrm{mg} / \mathrm{dL}$ and D-dimer of $>10,000$. Complete urine examination was normal without any RBC. INR was 1.23 . The diagnosis of placenta percreta with uterine rupture leading to intraperitoneal haematoma confirmed and proceeded with further management.

\section{Management}

Preoperatively, 1 unit of PRBC was transfused. High risk consent was taken. Patient was taken for emergency Hysterotomy. Consent for Hysterectomy in case of need was explained and obtained. Blood and blood products were arranged.

Intraoperative findings revealed $500 \mathrm{~mL}$ intraperitoneal blood clots. Uterine rupture was seen at the right side of previous lower segment scar with E/O placenta percreta seen. Delivered a dead baby of 250 gms. Placenta and membranes were extracted in bits.

Bilateral uterine artery ligation was done followed by modified mulberry stitches on uterus in view of atonic uterus.

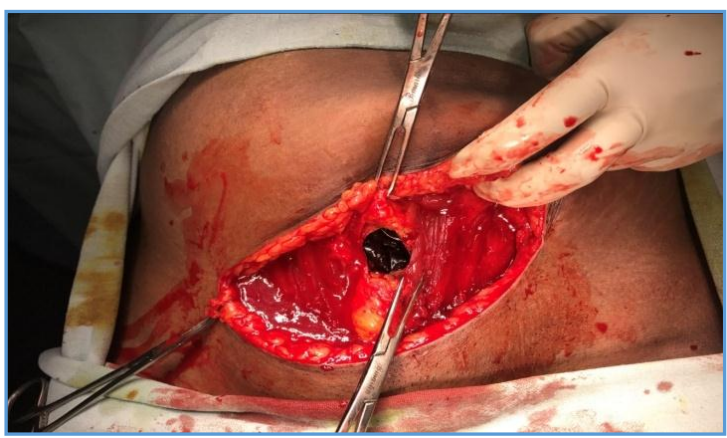

Evidence of Intraperitoneal Haematoma on Opening the Abdomen

'Financial or Other Competing Interest': None.

Submission 10-02-2018, Peer Review 10-03-2018,

Acceptance 16-03-2018, Published 25-06-2018.

Corresponding Author:

Dr. B. Radhika,

\#273, Jalvayu Vihar Colony,

KPHB, Hyderabad-72. Telangana.

E-mail: drradheeobg@yahoo.com drradheeobg@yahoo.com

DOI: $10.14260 /$ jemds $/ 2018 / 691$ 


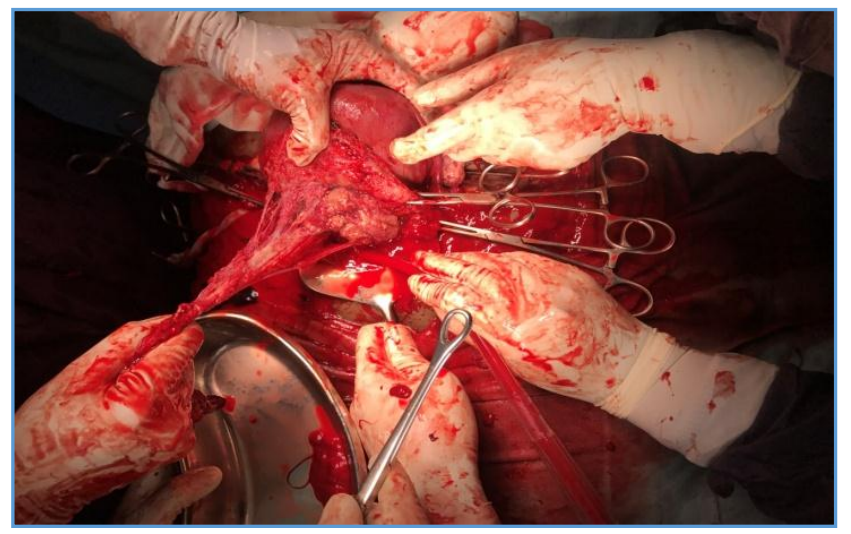

Completely Adherent Placenta invading outside the Serosa

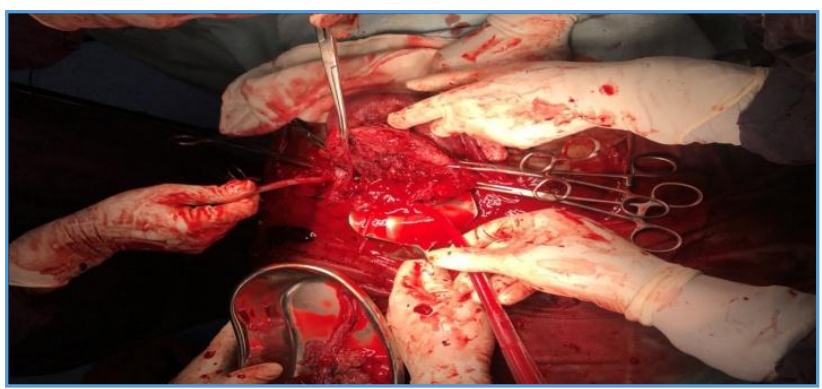

Endometrial Cavity after effectively removing the Entire Placenta

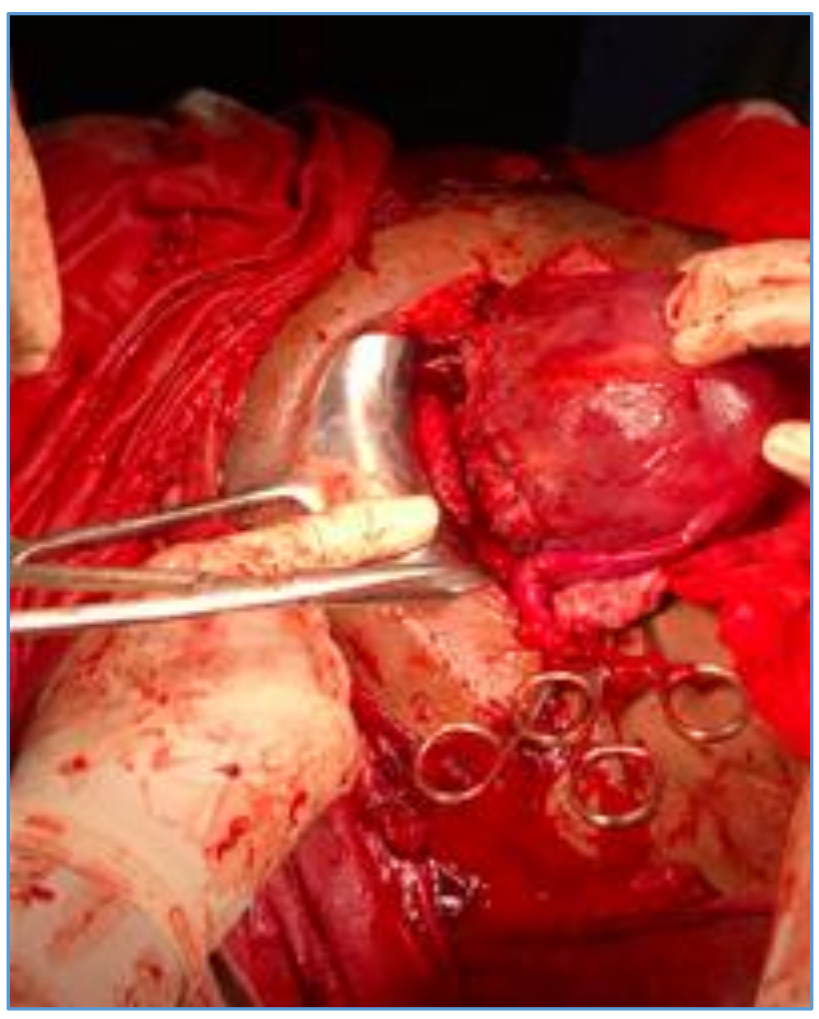

Final Picture of Uterus after Mulberry Sutures and Uterine Artery Ligation

Postoperatively, 7 units of fresh frozen plasma was transfused along with 5 units of PRBC. Injection Methotrexate $50 \mathrm{mg}$ was given intramuscularly along with Folinic acid $6 \mathrm{mg}$ IV given.
Patient was stable at the time of discharge. Beta HCG levels 48 hours post surgery was 506.88. Patient was followed up till Beta HCG became $<0.01$.

\section{DISCUSSION OF MANAGEMENT}

The incidence of placenta percreta has been increasing in the last few decades due to increasing incidence of lower segment caesarean sections.[1,2] Other predisposing conditions are instrumentation of the endometrium, placenta praevia, uterine malformations, septic endometritis, previous manual removal of placenta and multiparity. A risk of placenta percreta exists in 2 to $5 \%$ with any case of placenta praevia. In these cases, resuscitation procedures (when appropriate) and an urgent hysterectomy appears to be the treatment of choice. Antecedently, a conservative treatment, aiming at uterine rescue was followed to a greater extent based upon manual removal of as much placental tissue as possible. Fox et al reported that $25 \%$ of the women died during this treatment.[3] Under these circumstances, the more conservative treatment can be achieved only in cases of a partial placenta percreta/ increta when bleeding is minimal. Alternative interventions include ligature of uterine artery or internal iliac artery or angiographic embolisation. ${ }^{4]}$

There are a number of risk factors leading to haemoperitoneum during pregnancy. Previous gynaecological procedures, multiple pregnancies, infections, curettage, trophoblastic disease and endometrial or cervical malignancies favour such an occurrence.[5] Spontaneous uterine rupture may also follow adenomyosis, instrumental termination, manipulations during labour, misoprostolinduced labour or cocaine misuse. In some cases, no cause can be identified.

Magnetic resonance imaging and Doppler sonography can be used for the prenatal diagnosis of placenta increta. However, the diagnostic value of sonography in prenatal diagnosis of an asymptomatic placenta increta is uncertain. A positive predictive value of $78 \%$ and a negative predictive value of $94 \%$ has been reported by Finberg et al, but some of the other authors suggested that sonography might detect only around $33 \%$ of cases of placenta percreta/ increta.[6,7]

\section{CONCLUSION}

It is a potential life-threatening condition for both mother and the baby. In spite of early diagnosis of placenta percreta/increta through MRI, hysterectomy remains a common procedure. This case report highlights uterine artery ligation and mulberry stitch application to prevent intrapartum haemorrhage, thus saving the uterus. Use of Methotrexate to tackle any retained placental tissue is noted. This case also highlights need for further research into the prevention of abnormal placental development and to prevent their risk of massive haemorrhage.

\section{REFERENCES}

[1] Shnider S, Levinson G. Anesthesia for Obstetrics. 3 $3^{\text {rd }}$ edn. USA: Williams and Wilkins 1993.

[2] Gielchinsky Y, Rojansky N, Fasouliotis S, et al. Placenta accreta - summary of 10 years: a survey of 310 cases. Placenta 2002;23(2-3):210-4. 
[3] Shellhaas CS, Gilbert S, Landon MB, et al. The frequency and complication rates of hysterectomy accompanying cesarean delivery. Eunice Kennedy Shriver National Institutes of Health and Human Development Maternal-Fetal Medicine Units Network. Obstet Gynecol 2009;114(2 Pt 1):224-9.

[4] Liu X, Fan G, Jin Z, et al. Lower uterine segment pregnancy with placenta increta complicating first trimester induced abortion: diagnosis and conservative management. Chin Med J (Engl) 2003;116(5):695-8.
[5] Yang JJ, Xiang Y, Wan XR, et al. Diagnosis and management of uterine arteriovenous fistulas with massive vaginal bleeding. Int $\mathrm{J}$ Gynaecol Obstet 2005;89(2):114-9.

[6] Finberg HJ, Williams JW. Placenta accreta: prospective sonographic diagnosis in patients with placenta previa and prior cesarean section. J Ultrasound Med 1992;11(7):333-43.

[7] Lam G, Kuller J, McMahon M. Use of magnetic resonance imaging and ultrasound in the antenatal diagnosis of placenta accreta. J Soc Gynecol Investig 2002;9(1):37-40. 